Proceedings

\title{
Influence of Exercise Enrichment on Feedlot Cattle Behaviour and the Human-Animal Relationship ${ }^{\dagger}$
}

\author{
Emma J. Dunston-Clarke*, Isabella Hunter and Teresa Collins
}

Citation: Dunston-Clarke, E.J.;

Hunter, I.; Collins, T. Influence of

Exercise Enrichment on Feedlot

Cattle Behaviour and the Human-

Animal Relationship. 2021, 73, 4.

https://doi.org/10.3390/

IECA2020-08824

Published: 2 December 2020

Publisher's Note: MDPI stays neutral with regard to jurisdictional claims in published maps and institutional affiliations.

Copyright: $@ 2020$ by the authors. Licensee MDPI, Basel, Switzerland. This article is an open access article distributed under the terms and conditions of the Creative Commons Attribution (CC BY) license (http://creativecommons.org/licenses/by/4.0/).
School of Veterinary Medicine, College of SHEE, Murdoch University, Perth 6150, Australia; ihunter12@iprimus.com.au (L.H.); T.Collina@murdoch.edu.au (T.C.)

* Correspondence: Emma.Dunston@murdoch.edu.au

+ Presented at the 1st International Electronic Conference on Animals - Global Sustainability and Animals: Science, Ethics and Policy, 5-20 December 2020; Available online: https://ieca2020.sciforum.net/.

\begin{abstract}
Finding practicable and cost-effective enrichment for cattle in feedlots is challenging. While enrichment should not negatively impact productivity, it could assist in improving feedlot sustainability by addressing societal concern that cattle have restricted, unnatural lives. In a feedlot $250 \mathrm{~km}$ northeast of Perth, 287 mixed-breed Bos taurus cattle were provided with two different exercise treatments ( 1 = exercised in pen, 2 = exercised in laneway) and a control pen. Cattle were exercised using low-stress stock handling 2-3 times/week for approximately 20 min between days $40-80$ of a 120-day feeding program. Body weights, crush temperament and crush exit speeds were collected on days 40 and 80, while behavioural testing was conducted on days 41, 60 and 79 in home pens. Body weight was found to significantly increase for all pens, however, weight gains between treatments did not significantly differ $(p<0.05)$. However, a smaller and higher range of weight gains were found for exercised pens. The control pen had two animals lose weight, suggesting that while enrichment did not negatively impact productivity, there was a possible positive influence. Cattle exercised in the laneway were found to be less responsive and recovered quickly post exposure to a novel human. Cattle exercised in-pen were less reactive during avoidance and novel person tests, showing an improved human-animal relationship. This pilot study showed that exercise impacted cattle behaviour and the human-animal relationship, which could assist feedlot sustainability.
\end{abstract}

Keywords: environmental enrichment; novel person; aversion; reactivity index; ethogram; temperament

\section{Introduction}

The Australian feedlot industry houses $2-3 \%$ of the nation's cattle herd at any one time, employs 2000 people directly and contributes AUD 4.6 billion to the economy per year [1]. Feedlots facilitate the consistent supply of beef to domestic and interaction markets [2]. While cattle will only spend between 10-15\% of their life within feedlots [3], concern for how cattle are raised and treated is important to society [4,5]. Increasing consumer influence over livestock production systems means producers need to be aware of societal concerns and address these to maintain social licences to operate [5,6]. As pasture systems are considered gold standard by consumers, the unnatural environment of intensive farming systems, such as feedlots, must be considered by industry [7].

Various types of enrichment have been tested on housed cattle, predominately dairy cows and calves, including balls, ropes and other toys [8-10], mirrors, images, food puzzles [9-11], access to pasture [11,12] and brushes [8,11,13,14]. Many of these have resulted in habituation and non-use after a period, while access to brushes being the most effective for feedlot cattle, as reviewed by Wilson, Mitlöhner [15]. However, commercial feedlots do not necessarily have the resources to provide all cattle with either of these. Rather, an enrichment that utilises currently available resources would be ideal. Using exercise as a 
form of enrichment is still largely a new concept, with previous studies focusing on the acclimation [16] and impacts on productivity [17]. As low-stress stock handling accreditation increases in Australian feedlots, utilising these skills to provide an exercise enrichment to feedlot cattle could provide a type of enrichment that is more readily accessible.

Providing enrichment to feedlot cattle that is cost-effective and easily implementable, while encouraging positive human interactions yet not reducing productivity would be ideal. This study aimed to determine the effect of providing exercise, where cattle were moved either within their home pen or into the laneway, on cattle behaviour, productivity and the human-animal relationship.

\section{Material and Methods}

Animal Ethics was approved by Murdoch University (R3106/19). Between FebruaryApril 2019, 286 Bos taurus mixed-breed cattle were kept at a feedlot approximately $250 \mathrm{~km}$ northeast of Perth. Three pen treatments were provided; in-pen exercise (IP), out-of-pen laneway exercise (OP) and no exercise (Con). The Con pen was located at the end of a row, with the in-pen and laneway treatment pens situated next to each other in the same row. Stock handlers trained in low-stress stock handling exercised cattle for 20-30 min 2-3 times per week for the first 20 days, and for 10-20 min 2-3 times per week for the final 20 days of the study. The cattle were on a 120-day feed program, and enrichment was conducted on feed days $40-80$. On days 40 and 80 , all cattle were passed through the crush and weighed, and crush scores [18] and exit speeds of approximately $30 \%$ randomly selected cattle were recorded.

On days 41, 60 and 79, a novel person test, which is a new method adapted from previous studies that exposes both wildlife $[19,20]$ and domestic species $[21,22]$ to novel objects, and an avoidance test were conducted on cattle while in their home pens, between 07:30-11:00 h. Prior to the novel person test, three Inca 4K Action Cameras were placed on pen corners and left to film for $10 \mathrm{~min}$, with this footage analysed with a species-specific ethogram capturing posture and activity. One of the research team then entered one corner of the pen and walked diagonally across the pen at one step every $2 \mathrm{~s}$, with eyes gazed down and hands by their side. This footage was analysed for cattle reactions to human presence using a reactivity index [23]. Cameras were left to record for another 10 min for ethogram analysis to allow comparisons of cattle behaviour before and after novel person exposure. The same researcher was used as the novel person throughout the study.

An avoidance test within each pen was conducted $30 \mathrm{~min}$ after the novel person tests. One of the research team, different from the person used in the novel person test, entered calmly and stood in the middle of the pen, with their back to the majority of the cattle and head lowered for $2 \mathrm{~min}$ to allow cattle to acclimatise to human presence. The researcher slowly turned to face the cattle and in an anti-clockwise direction, faced an animal looking at the researcher and slowly approached the left shoulder. A step every $2 \mathrm{~s}$ pace was made and approach ceased as soon as the animal took one step back. The distance between the researcher and animal was estimated in metres. If an animal was lying down, the distances at which the animal stood up, and at which the animal took one step back were recorded. This was repeated for 20-30 cattle, per pen.

\section{Statistical Analysis}

Body weight change across the study was tested through Repeated Measures ANOVA, with weight difference tested for treatment effect via ANCOVA, with start weight fitted as a covariate. Crush score, exit speed and avoidance test data were tested for variance across the study via Friedman's tests and for treatment effect through Kruskal Wallis tests. Videos during the novel person test were analysed to provide the percentage of cattle per reactivity index category (no response, looked at person, stand up, approach, 
retreat at walk, retreat at run), via instantaneous scan sampling at $10 \mathrm{~s}$ intervals. Friedman's test was conducted to test for difference across the study and Kruskal Wallis test for treatment effect using SPSS, Version 24 [24].

Videos before and after the novel person test were analysed to provide the percentage of cattle per pen in a standing or lying posture, and activities of resting, vigilance, eating, drinking, ruminating, self-grooming, allo-grooming, exploratory behaviour, play behaviour and mounting. This was conducted via instantaneous scan sampling at $30 \mathrm{~s}$ intervals. Data were log-10 transformed prior to analysis via Repeated Measures ANOVAs to test for significance across treatments, days (days 41, 60 and 79) and timepoints (before (TP1) vs. after (TP2) novel person test) using Statistica, Version 13.5.0.17 [25].

Body weights for all treatments significantly increased $(p<0.001)$, with mean weight increase being $61.1 \mathrm{~kg}, 58.4 \mathrm{~kg}$ and $58.7 \mathrm{~kg}$, for Con, OP and IP, respectively. However, the amount of weight gained did not differ between pens, while two animals in the Con group recorded weight loss. While crush scores significantly decreased across the study, there was no significance between pens. Exit speeds did not significantly change across the study, nor did they differ between pens.

All pens had significantly different avoidance test distances for between treatments on days $41\left(\chi_{39}^{2}=9=954, p=0.009\right), 60\left(\chi_{81}^{2} 10.104, p=0.006\right)$ and $79\left(\chi_{89}^{2}=37.708, p=\right.$ 0.000 ) (Figure 1). Between days 40 and 80 , avoidance distances significantly decreased for Con $\left(\chi_{67}^{2}=20.364, p<0.001\right)$ and IP $\left(\chi_{77}^{2}=15.815, p<0.001\right)$, but not for OP. Overall, Con had the largest average decrease in avoidance distance $(5.8 \mathrm{~m})$, but also had the largest average avoidance distance on day $40(9.6 \mathrm{~m})$ compared to the OP $(6.3 \mathrm{~m})$ and IP $(4.8 \mathrm{~m})$. Cattle reactions to the novel person varied between pens across the study, with IP having the lowest 'no reaction' on day $41\left(\chi_{17}^{2}=8.4, p=0.015\right)$ but the highest on day $60\left(\chi_{17}^{2}\right.$ $=11.6, p=0.003)$. On day 41, Con 'looked' the least $\left(\chi_{17}^{2}=11.0, p=0.004\right)$ while OP 'retreated at a walk' the least $\left(\chi_{17}^{2}=6.1, p=0.048\right)$. On day 60 , IP 'retreated at a walk' $\left(\chi_{17}^{2}=11.6, p\right.$ $=0.003)$ and 'at a run' the least $\left(\chi_{\mathbf{1 7}}^{2}=10.9, p=0.004\right)$. Behaviour did not significantly differ between pens on day 79. Both Con $\left(\chi_{17}^{2}=12.0, p=0.002\right)$ and OP $\left(\chi_{17}^{2}=7.6, p=0.002\right)$ increased 'looking' at the novel person across the study, while 'retreat at run' decreased for Con $\left(\chi_{17}^{2}=7.2, p=0.028\right)$, on day 79 for OP $\left(\chi_{17}^{2}=6.3, p=0.042\right)$ and day 60 for IP $\left(\chi_{17}^{2}\right.$ $=9.5, p=0.009)$. 'Retreat at walk' was lowest on day 39 for Con $\left(\chi_{17}^{2}=6.3, p=0.042\right)$ and day 60 for IP $\left(\chi_{17}^{2}=10.3, p=0.006\right)$. IP had more 'no reaction' on day $60\left(\chi_{17}^{2}=10.3, p=\right.$ 0.006) (Figure 1).

A.

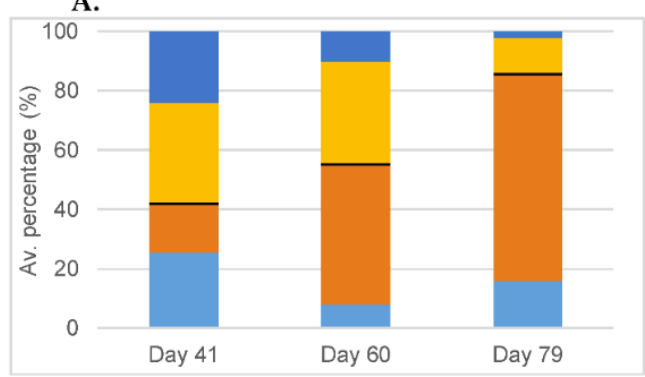

B.

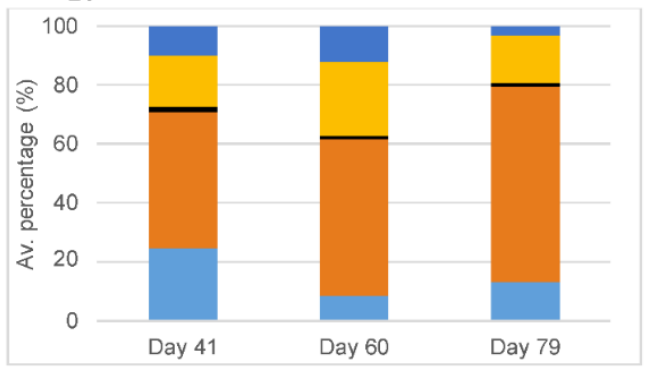

C.

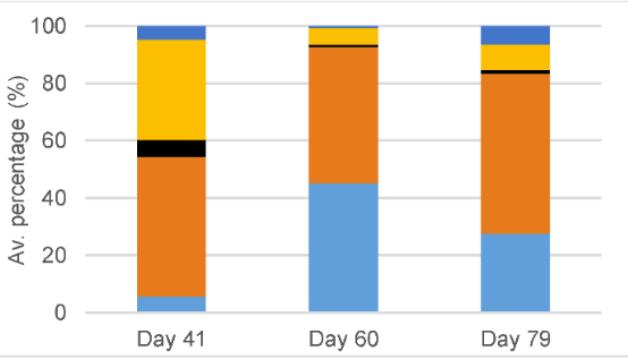

No reaction $\square$ Look $\quad$ Approach

Retreat at walk $\square$ Retreat at run

Figure 1. Average percentage of each pen per reactivity index response to the novel person test for; (A) Con, (B) OP and (C) IP, per day. 
Nine of the 11 behaviours significantly differed across day, time point (TP) and treatment (Figure 2). The percentage of each pen standing significantly changed across all days $\left(\mathrm{F}_{4,228}=114.0, p<0.001\right)$; on day 41 for TP1, Con and IP were standing more than OP, while at TP2, Con were standing more than exercise pens, and IP more than OP. For TP1 on day 60, treatments pens were standing more than Con. For TP1 on day 79, OP were standing more than Con and IP, and Con more than IP, while at TP2, exercise pens were standing more than Con. Across TPs, Con were standing less at TP2, while more IP were standing more at TP2. For TP1, Con and IP were standing more on day 41 than days 60 and 79, and for Con more on day 60 than 79, while OP were standing least on day 41. For TP2 Con were standing more on day 41 than days 60 and 79, while least were standing for OP on day 41 (Figure $2 \mathrm{~A})$. For resting $\left(\mathrm{F}_{4,228}=17.6, p<0.001\right)$, for TP1 on day 60 , OP were resting more than Con and IP, and IP less than Con, while for TP2, Con were resting less than exercise pens. For TP1, OP were resting more on day 60 than 41, IP cattle were resting more on day 79 than 41 and 60. For TP2, Con cattle were resting more on days 41 and 79 than 60, while OP cattle were resting more on day 60 and IP cattle more on day 60 than 41 and 79 (Figure 2B). For vigilance $\left(\mathrm{F}_{4,228}=46.3, p<0.001\right)$, Con cattle were less vigilant than exercise pens at TP1 on day 41 , with Con cattle becoming more vigilant at TP2. On day 60, IP were more vigilant than OP at TP1, while Con were more vigilant than exercise pens at TP2. Con cattle were more vigilant at TP2 than TP1, while IP were more vigilant at TP1 than at TP2. For TP1 on day 79, OP were more vigilant than IP and Con, while both Con and IP were more vigilant at TP2 than TP1. For TP1, Con and IP were more vigilant on days 41 and 60 than 79, while OP were more on days 41 and 79 than 60. For TP2, Con were more vigilant on day 60 than 41 and 79 , and more on day 41 than 79 , while OP were more on day 41 than 60, and IP more on days 41 and 79 than 60 (Figure 2C). For ruminating $\left(\mathrm{F}_{4,228}=39.4, p<0.001\right)$, exercise pens were ruminating more than Con at TP2 on day 41, with IP ruminating more at TP2 than TP1. For TP2 on day 60, IP were ruminating more than Con and OP, and were also again ruminating more at TP2 than TP1. For TP1 on day 79 , IP were ruminating more than OP, but were ruminating more at TP1 than TP2. For TP1, all pens were ruminating more on days 60 and 79 than 41, with IP also more on day 79 than 60. For TP2, all pens were ruminating less on day 41 than 79, while for Con and IP, day 41 was also less than 60 and day 60 was less than 79 for Con (Figure 2D). For selfgrooming $\left(\mathrm{F}_{4,228}=6.7, p<0.001\right)$, IP were self-grooming less than Con for TP1 on day 41, while Con were less than OP at TP2 and more at TP1 than TP2.

For day 79, Con were self-grooming more at TP2 than exercise pens. Con were selfgrooming more on days 41 and 79 than 60 for TP1, and less on days 41 and 60 than 79 for TP2 (Figure 2E). For allo-grooming $\left(\mathrm{F}_{4,228}=9.4, p<0.001\right)$, Con were allo-grooming more than exercise pens at TP1 and more at TP1 than TP2. For day 79, Con were allo-grooming more than OP at TP2. Con were allo-grooming more on day 41 than 60 and 79 for TP1, and less on day 41 than 79 for TP2 (Figure 2F). For drinking $\left(\mathrm{F}_{4,228}=7.1, p<0.001\right)$, Con were drinking more than IP at TP1, while OP were drinking more than IP and Con at TP2 and IP were drinking more at TP2 than TP1. For day 60, IP were drinking more than OP at TP1 and more than Con and OP at TP2. For day 79, IP were drinking more than OP and Con at TP1, while OP were drinking less than Con and IP at TP2. Both Con and OP were drinking more on days 41 and 60 than 79, while IP were drinking less on day 41 than 60 and 79, and less on day 79 than 60, for TP1. For TP2, Con were drinking more on day 60 than 79, IP more on days 41 and 79 than 60 , and for OP, more on days 60 and 79 than 41 , and more on day 60 than 79 (Figure $2 \mathrm{G})$. For eating $\left(\mathrm{F}_{4,228}=26.0, p<0.001\right)$, Con were eating less than OP and IP for TP1 and TP2 on day 41, with IP more at TP2 than TP1. For day 60, Con were eating more than exercise pens and IP more than OP at TP1, while both OP and IP were eating more at TP2 than TP1. For day 79, Con and IP were eating more than OP at TP1, with Con and OP more than IP at TP2, while OP were eating more at TP2 than TP1, and IP more at TP1 than TP2. Con were eating less on day 41 than 60 and 79 and day 60 less than 79, while OP were eating more on day 79 than 41 and 60, and IP more on day 41 than 60 but less than day 79 for TP1. For TP2, Con were eating less on day 41 than 60 
and 79, while OP were eating less on day 60 than 79 and IP were eating more on day 41 than 60 and 79, and more on day 60 than 79 (Figure $2 \mathrm{H})$. For playing $\left(\mathrm{F}_{4,228}=5.2, p<0.001\right.$ ), Con were playing more than exercise pens at TP1, more than OP at TP2 on day 41, with more playing at TP1 than TP2. Con were playing more on day 41 than days 60 and 79 for TP1.

A.

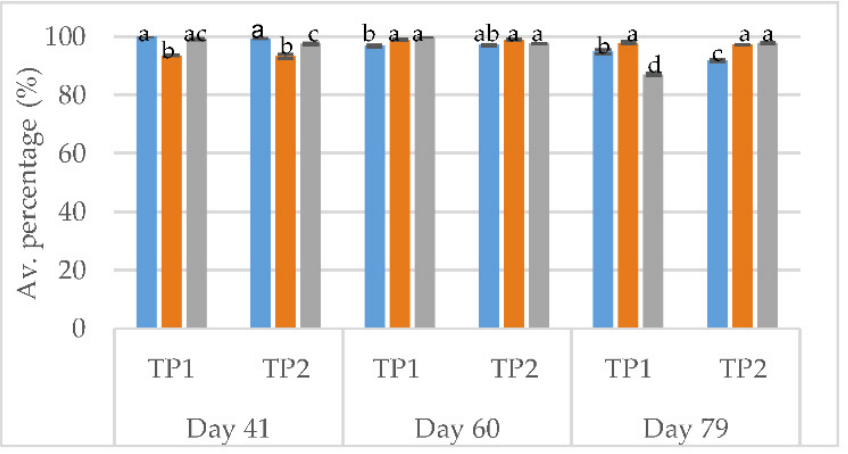

B.

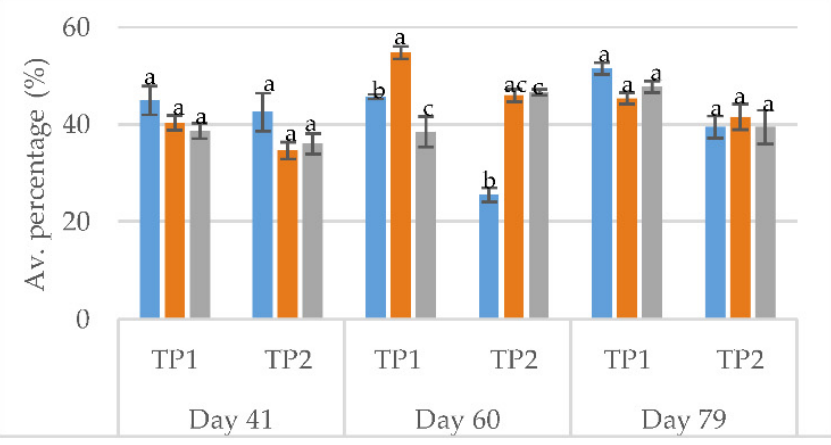

C.

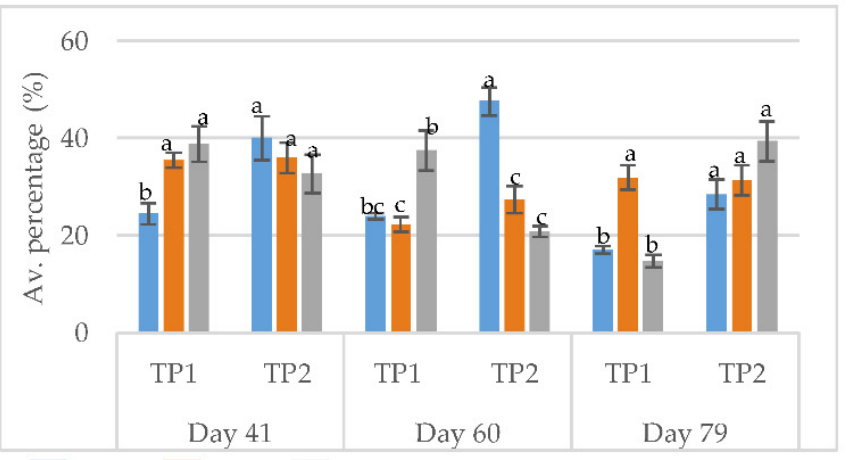

Con OP IP
D.

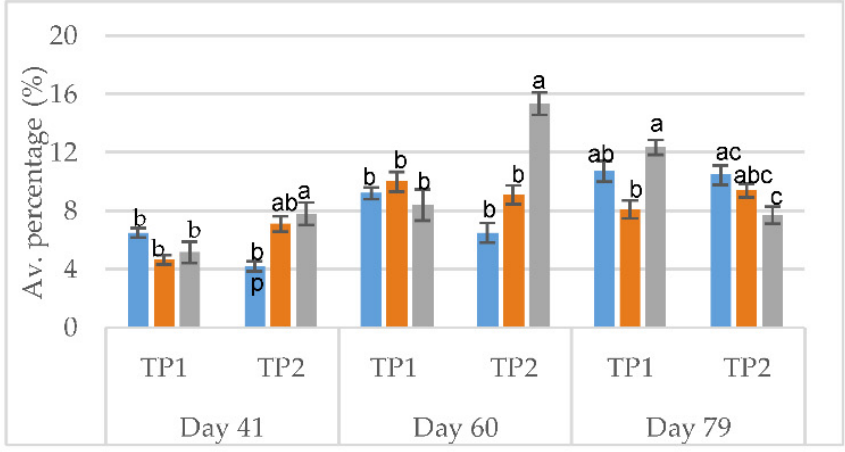

E.

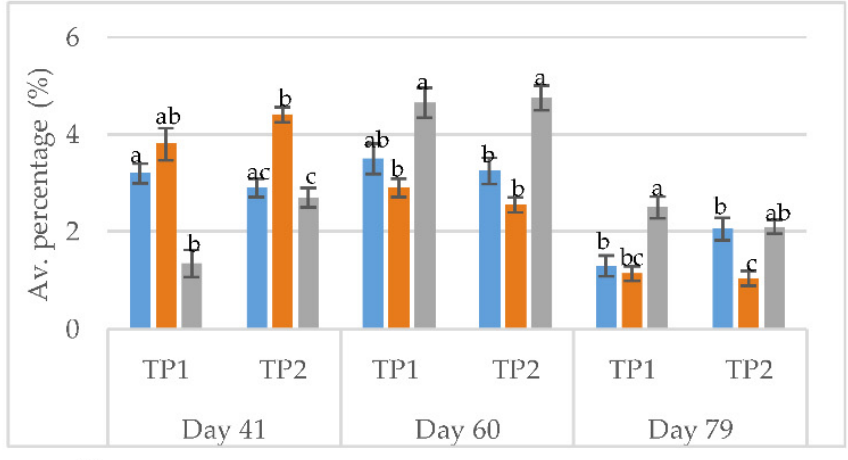

F.

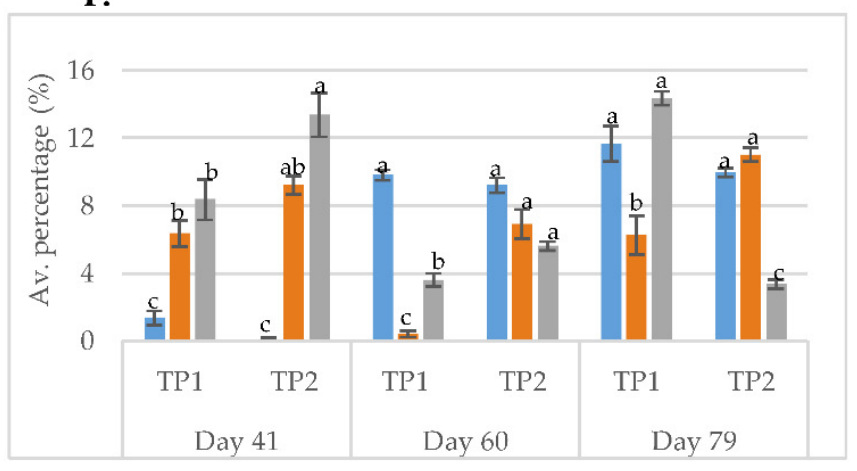

Figure 2. Average percentage $( \pm S E)$ of each pen $(\mathbf{A})$ standing, $(\mathbf{B})$ resting, $(\mathbf{C})$ vigilant, $(\mathbf{D})$ ruminating, $(\mathbf{E})$ drinking and (F) eating, before (TP1) and after (TP2) the novel person test, per day. Note: letters indicate Tukey's significance between pens within a time point (TP) and between pens within a day.

\section{Discussion}

This novel study assessed the influence on exercise on cattle behaviour and productivity in an Australian feedlot. Exercise showed no adverse effects on productivity, but reduced cattle reactivity to humans in their pens. While weight gains did not significantly differ between treatments, the control pen had two individuals that lost weight and one with a low weight gain $(15 \mathrm{~kg})$, resulting in a larger distribution in weight difference across the 40 days. Exercise treatment pens had a smaller distribution of weight gains, particularly the OP pen, indicating that more cattle had higher gains. While increased 
movement could be speculated to result in weight loss, our finding that all cattle under exercise treatments gained weight is supported elsewhere [26-28]. A previous US study found exercise resulted in smaller weight gains and a leaner carcass but cattle were provided longer exercise periods (up to $40 \mathrm{~min}$ ) [17]. Hence the duration and frequency of exercise could be manipulated to permit cattle to meet their market targets. Our weight differences and behavioural responses may have been different if the study was conducted over cooler months, noting temperatures $>30^{\circ} \mathrm{C}$ dry bulb occurred over most of the study. During periods of high heat, cattle will typically reduce or alter their feeding patterns, directing energy towards thermoregulation during the heat of the day [29,30]; however, a panting score $>2.5$ (out of 4.5) [29] was not observed during data collection. Replicating this study over the full feeding period and during colder months is required. It is speculated that exercise encourages social mixing and leads to improved social dynamics, reduced bulling at feed and water resources and encourages all cattle to eat $[12,26,27]$; this was supported by more cattle being observed to eat, drink and ruminate more after the novel person exposure. While all treatments had a decrease in avoidance distance across the study, which is expected to occur as cattle acclimatise to feedlot husbandry, the IP cattle had a large decrease in avoidance distance and became less reactive to human presence for the novel person test across the study, indicating this exercise type impacted cattle responses to humans. This is supported by the OP treatment pen only having a small decrease in avoidance distance. This pen was provided access to the laneway for exercise, with staff only encouraging cattle to exit and re-enter the pen, rather than providing continued pressure and release that was applied to the IP to encourage cattle movement. While providing exercise enrichment needs further testing across an entire feed program, this study indicates that exercise can provide multiple benefits to cattle, including ease of handling and weight gain. This may improve cattle quality of life and ensure feedlot sustainability.

Author Contributions: Conceptualization, methodology: E.J.D.-C., T.C.; investigation, writing, original draft preparation: E.J.D.-C., I.H.; writing, review, editing: E.J.D.-C., T.C. All authors have read and agreed to the published version of the manuscript.

Funding: This research was funded by a School of Veterinary Science, Murdoch University, Vet Trust Grant.

Institutional Review Board Statement: Animal ethics for the project was provided by Murdoch University Animal Ethics Committee R3106/19.

Informed Consent Statement: Informed consent was obtained from all subjects involved in the study.

Data Availability Statement: The data presented in this study are available on request from the corresponding author. The data are not publicly available due to commercial sensitivity.

Acknowledgments: The authors wish the thank the feedlot for their support and contribution to the study.

Conflicts of Interest: The authors declare no conflict of interest.

\section{References}

1. ALFA. Industry Snapshot. Available online: https://www.feedlots.com.au/overview (accessed on 19 November 2020).

2. MLA. Feedlot Management. 2020. Available online: https://www.mla.com.au/research-and-development/feedlot/ (accessed on 19 November 2020).

3. ALFA. Frequently Asked Questions. Available online: https://www.feedlots.com.au/faq\#: :text=Australian\%20feedlot\%20cattle\%20spend\%20around,\%2D15\%25\%20of\%20their\%20lifespan (accessed on 19 November 2020).

4. Grandin, T. Animal welfare and society concerns finding the missing link. Meat Sci. 2014, 98, 461-469.

5. Coleman, G.; Hemsworth, L.; Acharya, R. Monitoring Public Attitudes to Livestock Industries and Livestock Welfare. FinalReport APL Project 2018/0014. 2019. Available online: https://www.awstrategy.net/uploads/1/2/3/2/123202832/nawrde_no._20180014_final_report.pdf (accessed on 19 November 2020). 
6. Hocquette, J.F.; Ellies-Oury, M.P.; Lherm, M.; Pineau, C.; Deblitz, C.; Farmer, L. Current situation and future prospects for beef production in Europe-A review. Asian-Australas. J. Anim. Sci. 2018, 31, 1017-1035.

7. Walker, J.; von Keyserlingk, M.A.G. Providing Assurance that Cattle Have a Reasonably Good Life, in the Welfare of Cattle; Engle, T., Klingborg, D.J., Rollin, B.E., Eds.; CRC Press: Boca Raton, FL, USA, 2018; pp. 109-123.

8. Bulens, A.; Van Beirendonck, S.; Van Thielen, J.; Driessen, B. The Effect of Environmental Enrichment on the Behaviour of Beef Calves. In Conference on the Assessment of Animal Welfare at Farm and Group Level; WAFL: Clermont-Ferrand, France, 2014.

9. Mandel, R.; Wenker, M.L.; van Reenen, K.; Keil, N.M.; Hillmann, E. Can access to an automated grooming brush and/or missor reduce stress of dairy cows kept in social isolation? Appl. Anim. Behav. Sci. 2019, 211, 1-8.

10. Stanford, K.; Silasi, R.; McAllister, T.A.; Schwartzkopf-Genswein, K.S. Behavior of feedlot cattle affects voluntary oral and physical ineractions with manila ropes. J. Anim. Sci. 2009, 87, 296-303.

11. Mandel, R.; Whay, H.R.; Klement, E.; Nicol, C.J. Invited review: Environmental enrichment of dairy cows and calves in indoor housing. J. Dairy Sci. 2016, 99, 1695-1715.

12. Castro, I.M.; Gygax, L.; Wechsler, B.; Hauser, R. Increasing the interval between winter outdoor exercise aggravates agonistic interactions in Herens cows kept in tie-stalls. Appl. Anim. Behav. Sci. 2011, 129, 59-66.

13. DeVries, T.J.; Vankova, M.; Veira, D.M.; Von Keyserlingk, M.A.G. Short Communication: Usage of Mechanical brushes by lactating dairy cows. J. Dairy Sci. 2007, 90, 2241-2245.

14. Uren, J.E. Environmental enrichment of calves using stationary and mechanical brushes. In Department of Animal Sciences; The Ohio State University: Columbus, OH, USA, 2018.

15. Wilson, S.C.; Mitlöhner, F.M.; Morrow-Tesch, J.; Dailey, J.W.; McGlone, J.J. An assessment of several potential enrichment devices for feedlot cattle. Appl. Anim. Behav. Sci. 2002, 76, 259-265.

16. Batterham, T. Benefits of Acclimation; Meat and Livestock Australia: North Sydney, Australia, 2018; pp. 1-139.

17. Gerlach, B.M. The effects of exericse on beef cattle health, performance, and carcass quality; and the effects of extended aging, blade tenderization, and degree of doneness on beef arome volatile formation. In Department of Animal Sciences and Industry College of Agriculture; Kansas State University: Manhattan, KS, Usa, 2014; pp. 1-202.

18. Grandin, T. Behavioral agitation during handling of cattle is persistent over time. Appl. Anim. Behav. Sci. 1993, 36, 1-9.

19. Bremner-Harrison, S.; Prodohl, P.A.; Elwood, R.W. Behavioural trait assessment as a release criterion: Boldness predicts early death in a reintroduction programme of captive-bred swift fox (Vulpes velox). Anim. Conserv. 2006, 7, 313-320.

20. Sinn, D.L.; Cawthen, L.; Jones, S.M.; Pukk, C.; Jones, M.E. Boldness towards novelty and translocation success in captive-raised, orphaned Tasmania devils. Zoo Biol. 2013, 33, 36-48.

21. Hemsworth, P.H.; Price, E.O.; Borgwardt, R. Behavioural responses of domestic pigs and cattle to humans and novel stimuli. Appl. Anim. Behav. Sci. 1996, 50, 43-56.

22. Foris, B.; Zebunke, M.; Langbein, J.; Melzer, N. Evaluating the temporal and situational consistency of personality traits in adult dairy cattle. PLoS ONE 2018, 13, e0204619.

23. Dunston-Clarke, E.; Willis, R.S.; Fleming, P.A.; Barnes, A.L.; Miller, D.W.; Collins, T. Developing an animal welfare assessment protocol for livestock transported by sea. Animals 2020, 10, 705.

24. Corp, I. IBM SPSS Statistics; Version 24; IBM Corp: Armonk, NY, USA, 2016.

25. TIBCO Software Inc. Statistica, Version 13.5.0.17.; TIBCO Software Inc.: Palo Alto, CA, USA, 2018.

26. Daigle, C.L.; Jackson, B.; Gill, R.; Wickersham, T.A.; Sawyer, J.E. Impact of exercise on productivity, behavior, and immune functioning of weaned Bos indicus- cross calves housed in drylots. J. Anim. Sci. 2017, 95, 5230-5239.

27. Wilson, M. Work out wonders: Happy cows may come from feedlots that exercise. Angus Beef Bulletin, October 2006, pp. 58-59.

28. Daigle, C.L.; Mathias, A.J.; Ridge, E.E.; Gill, R.; Wickersham, T.A.; Sawyer, J.E. Case Study: Effect of exercise programs during receiving in a commercial feedlot on behavior and productivity of Brahman crossbred calves: Results from a commercial environment and a comparison to the research environment. Prof. Anim. Sci. 2018, 34, 653-663.

29. Jubb, T.; Perkins, N. Veterinary Handbook for Cattle, Sheep E Goats; Meat and Livestock Australia and LiveCorp, North Sydney, Australia, 2012.

30. Hill, L.D.; Wall, E. Weather influences feed intake and feed efficiency in a temperate climate. J. Dairy Sci. 2017, 100, $2240-2257$. 